ISSN 2079-9292

www.mdpi.com/journal/electronics

Review

\title{
A Compact Dual-Mode Wearable Antenna for Body-Centric Wireless Communications
}

\section{Chia-Hsien Lin * and Koichi Ito}

Center for Frontier Medical Engineering, Chiba University, 1-33 Yayoi-cho, Inage-ku, Chiba-shi 263-8522, Japan; E-Mail: derek228015@gmail.com

* Author to whom correspondence should be addressed; E-Mail: ito.koichi@faculty.chiba-u.jp; Tel.: +81-43-290-3326; Fax: +81-43-290-3327.

Received: 20 February 2014; in revised form: 3 May 2014 / Accepted: 22 May 2014 /

Published: 1 July 2014

\begin{abstract}
The miniaturization of electronic devices is leading to the creation of body-centric wireless communications (BCWCs), in which wireless devices are attached to the human body. In particular, personal healthcare is considered as the biggest potential application. In this paper, we propose a compact wearable dual-mode (on-body and off-body modes) antenna for personal healthcare systems. For on-body mode at $10 \mathrm{MHz}$, received voltages are analyzed with a chest phantom, while for the off-body mode in the $2.4 \mathrm{GHz}$ ISM band, reflection coefficient $\left(S_{11}\right)$ and radiation patterns are studied.
\end{abstract}

Keywords: body-centric wireless communications (BCWCs); healthcare; wearable; dual-mode antenna

\section{Introduction}

In recent years, body-centric wireless communications (BCWCs) have become a very active area of research because of their numerous applications in areas such as personal health care, smart homes, personal entertainment, and identification systems [1-5]. In particular, many researchers consider personal health care as the biggest potential application of BCWCs, an area where many kinds of wireless medical devices are attached to the human body [2]. 
The operation frequency bands for body-centric wireless communications from tens of $\mathrm{MHz}$ to $\mathrm{GHz}$ bands were studied. Figure 1 shows the simulated electric field distributions around the human body at 3, 30, 300 and $3000 \mathrm{MHz}$. From the results, the lower frequencies (3 and $30 \mathrm{MHz}$ ) signals propagate along the human body while the higher frequency signals (300 and $3000 \mathrm{MHz}$ ) radiate outside the human body. Therefore, we utilized the characteristics of electric field distribution to design a novel antenna for body-centric wireless communications. In addition, it should be noted that the input power is very low at the low frequencies, as shown in Figure 2 [6].

Figure 1. Electric field distributions at different frequency points.

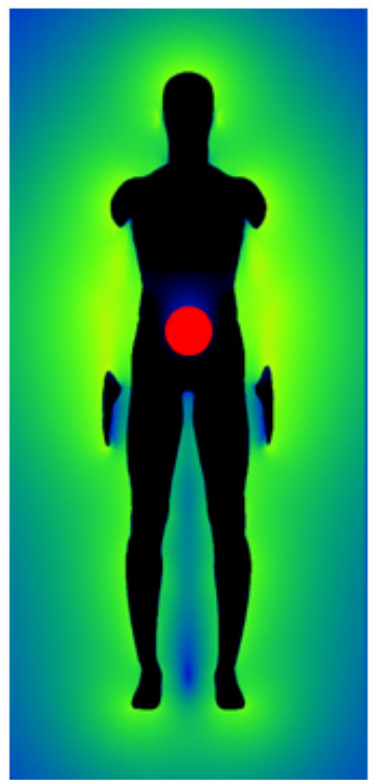

$3 \mathrm{MHz}$

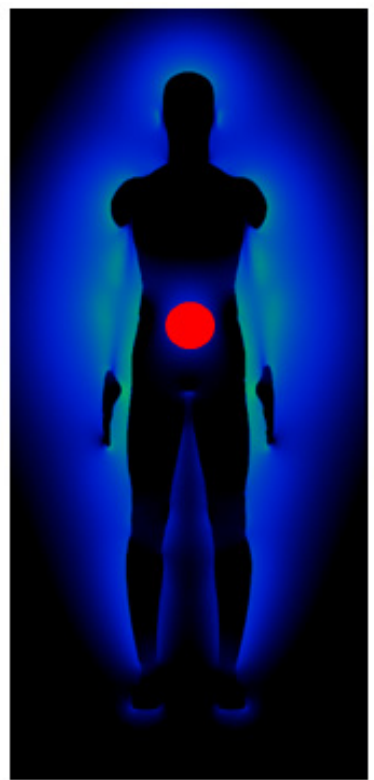

$30 \mathrm{MHz}$

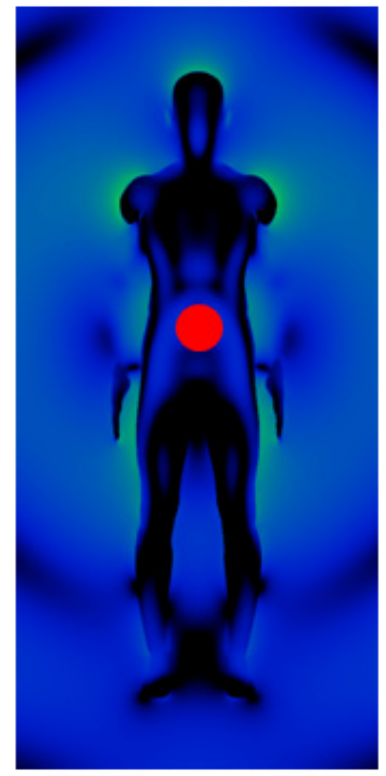

$300 \mathrm{MHz}$

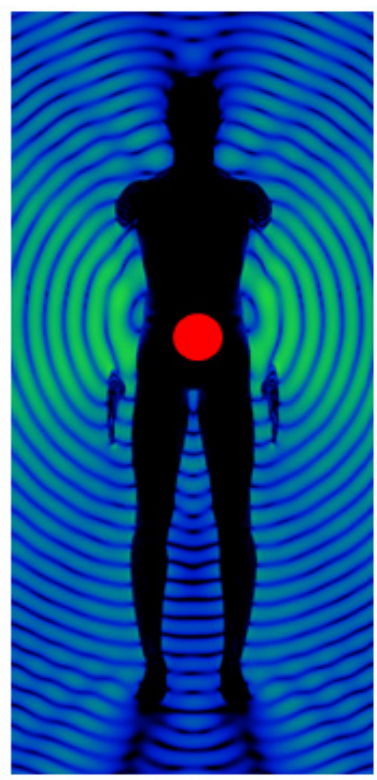

$3 \mathrm{GHz}$

Figure 2. Input power when $1-\mathrm{V}$ input is assumed.

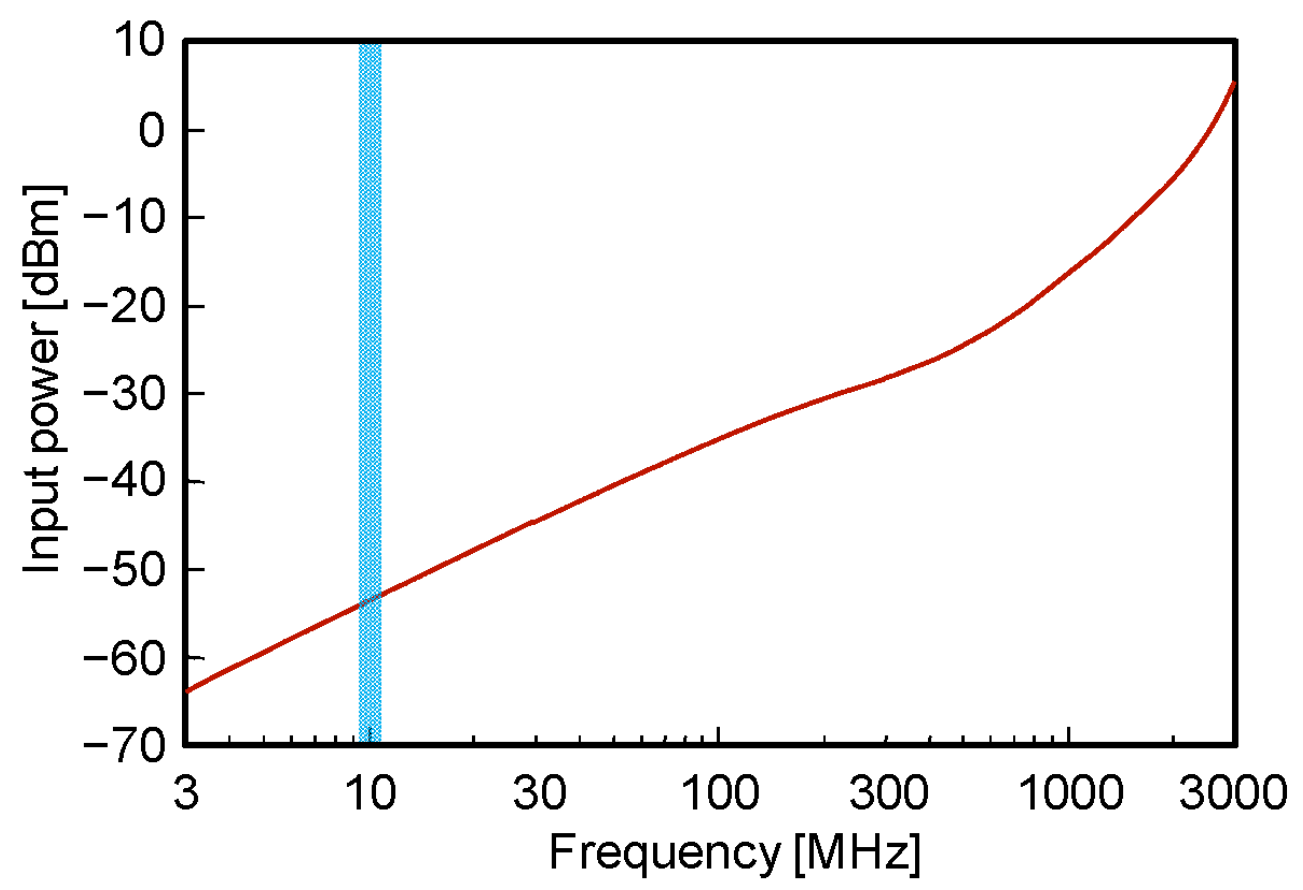


In personal health-care systems, at least two modes of communication are required: on-body mode (collecting medical data) and off-body mode (exchanging data with outside networks) [7]. For on-body communications, the communication range is limited on the human body. Both wearable transmitter and receiver are mounted on the surface of the human body, and biophysical signal can be transmitted along the human body. Off-body communications present the communication from the surface of the human body to a nearby external device. At least one antenna is located on the human body, and biophysical signal can be transmitted from the antenna on the human body to the external device [2]. Thus, a dual-mode antenna is a key component for the personal health-care system. For example, some sensors and a data controller (proposed dual-mode antenna) are mounted on the human body, as shown in Figure 3. The medical information is transmitted to the data controller by the transmitter at $10 \mathrm{MHz}$ (blue path). After the information is received, the data controller sends it to an external device by ISM band at $2.45 \mathrm{GHz}$ (red path). Therefore, the personal health-care system can be achieved by the proposed dual-mode wearable antenna [8].

Figure 3. Proposed medical application [8].

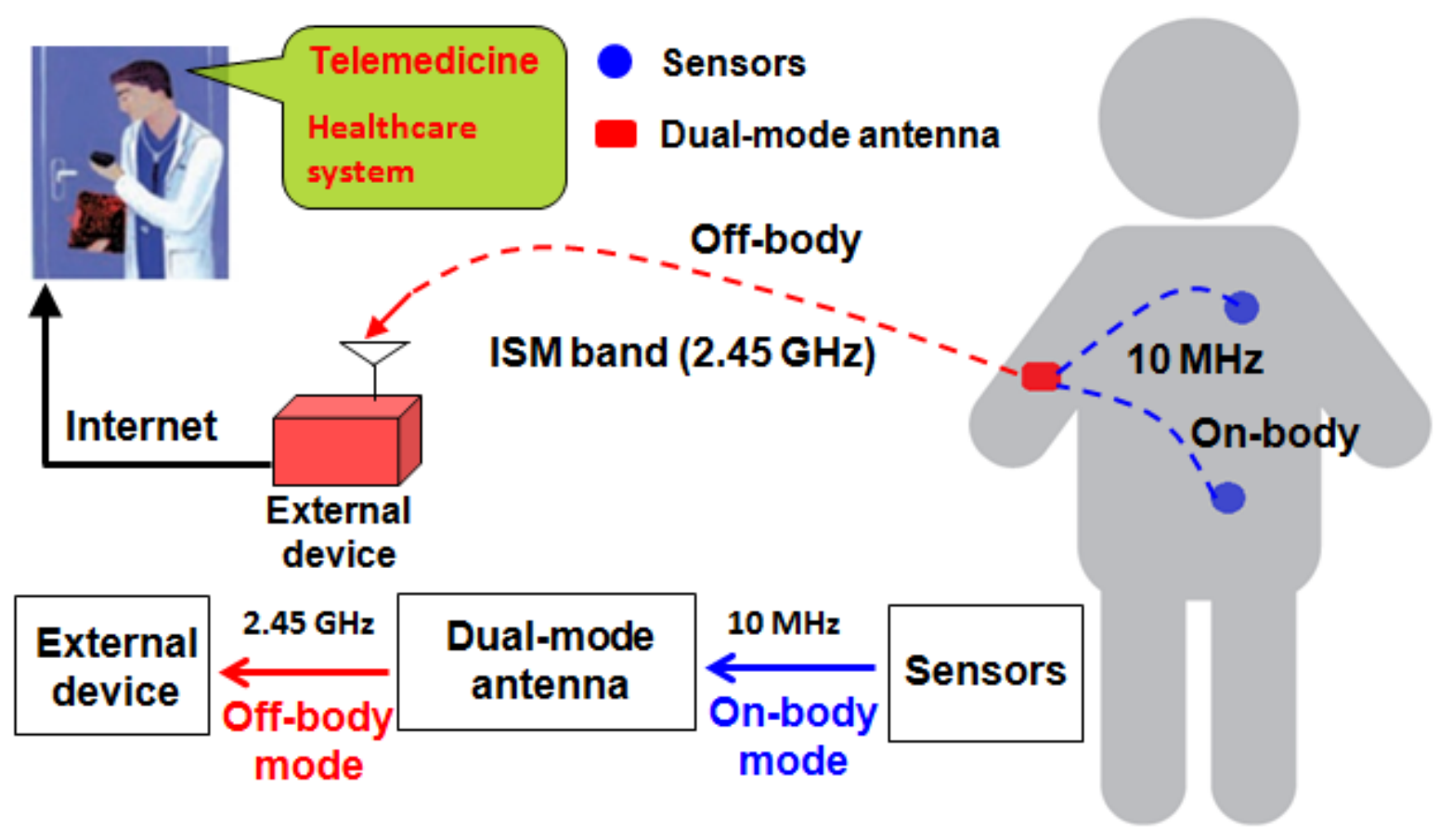

\section{Antenna Design and Human Body}

Figure 4 presents the proposed dual-mode wearable antenna. It consists of a feeding pin, a signal electrode, and a GND electrode. The size of the proposed antenna is $30 \times 33 \times 4 \mathrm{~mm}^{3}$. The height of the signal electrode and GND electrode are $4 \mathrm{~mm}$, and the feeding pin is located at the center of the signal electrode. The ISM band $(2.45 \mathrm{GHz})$ is resonated by the folded ground structure. In our antenna design, in terms of equipment packaging, we placed a plastic $\left(\varepsilon_{r}=3\right)$ with $2 \mathrm{~mm}$ in thickness between the antenna and the human body, as shown in Figure 5. Moreover, to confirm the performance of the proposed antenna on the human body and simplify the measurement process, we used a part of chest phantom (2.45 GHz: electrical constant $\varepsilon_{r}=35.2$, conductivity $\sigma=1.16 \mathrm{~S} / \mathrm{m}$ ) [9] to replace the whole 
human body. However, radiation characteristic of the proposed antenna on the human body should be realized; therefore, the proposed dual-mode antenna on a high-resolution human model in $1.75 \mathrm{~m}$ provided by National Institute of Information and Communication Technology (NICT) in Japan is also analyzed in our work, as shown in Figure 6. All simulated and measured results will be discussed in Section 3.

Figure 4. Structure of the proposed dual-mode antenna.

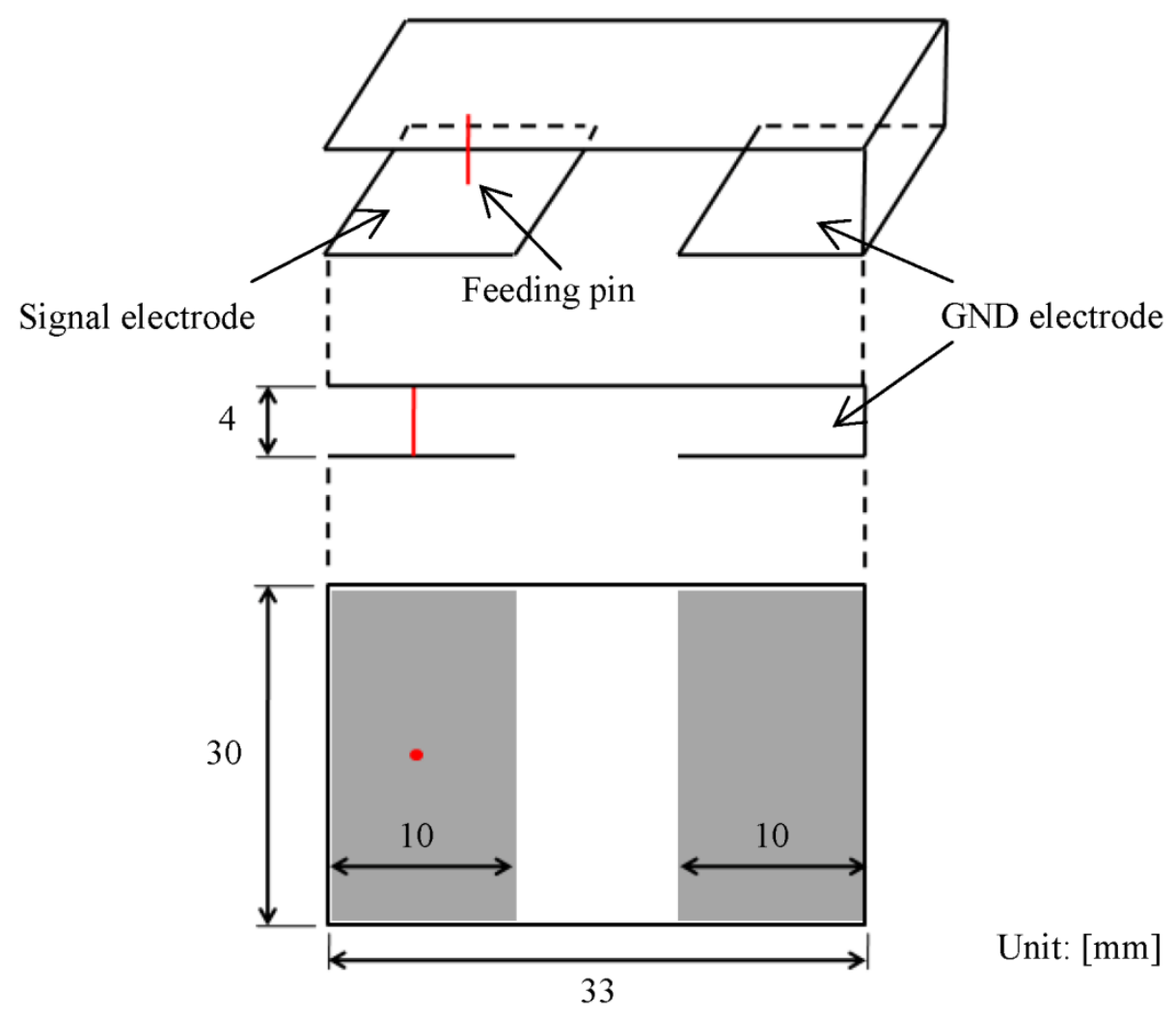

Figure 5. Proposed antenna on a part of chest phantom.

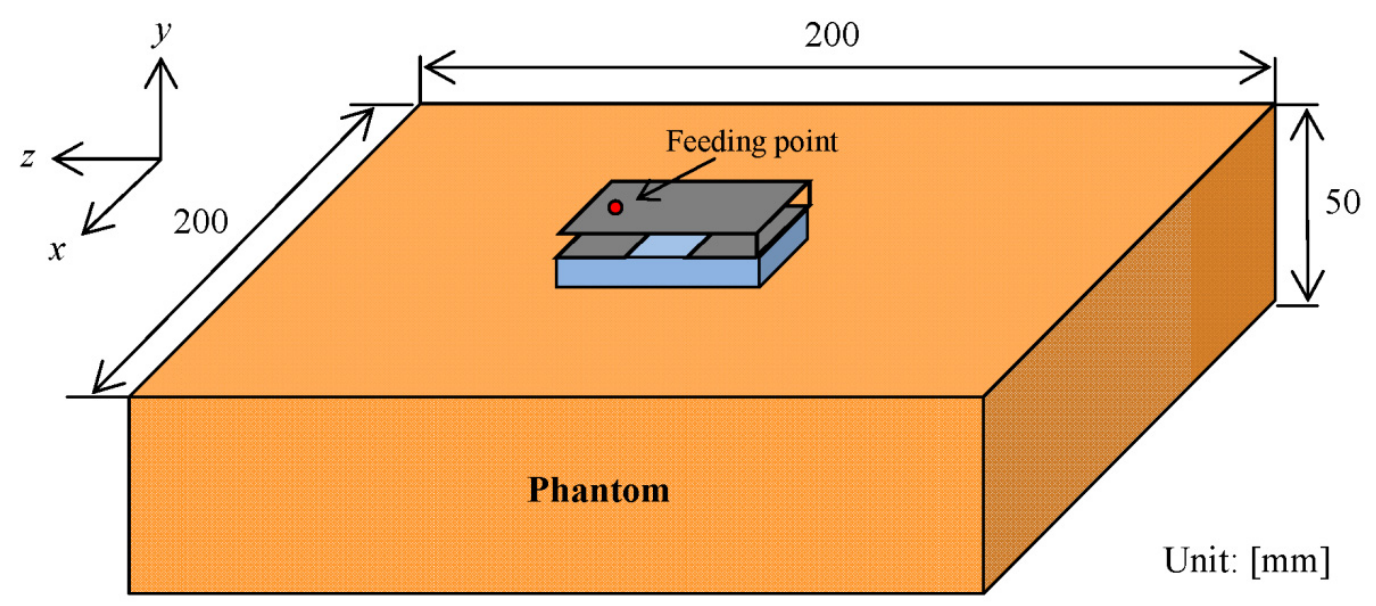


Figure 6. Proposed antenna on a high-resolution human model.

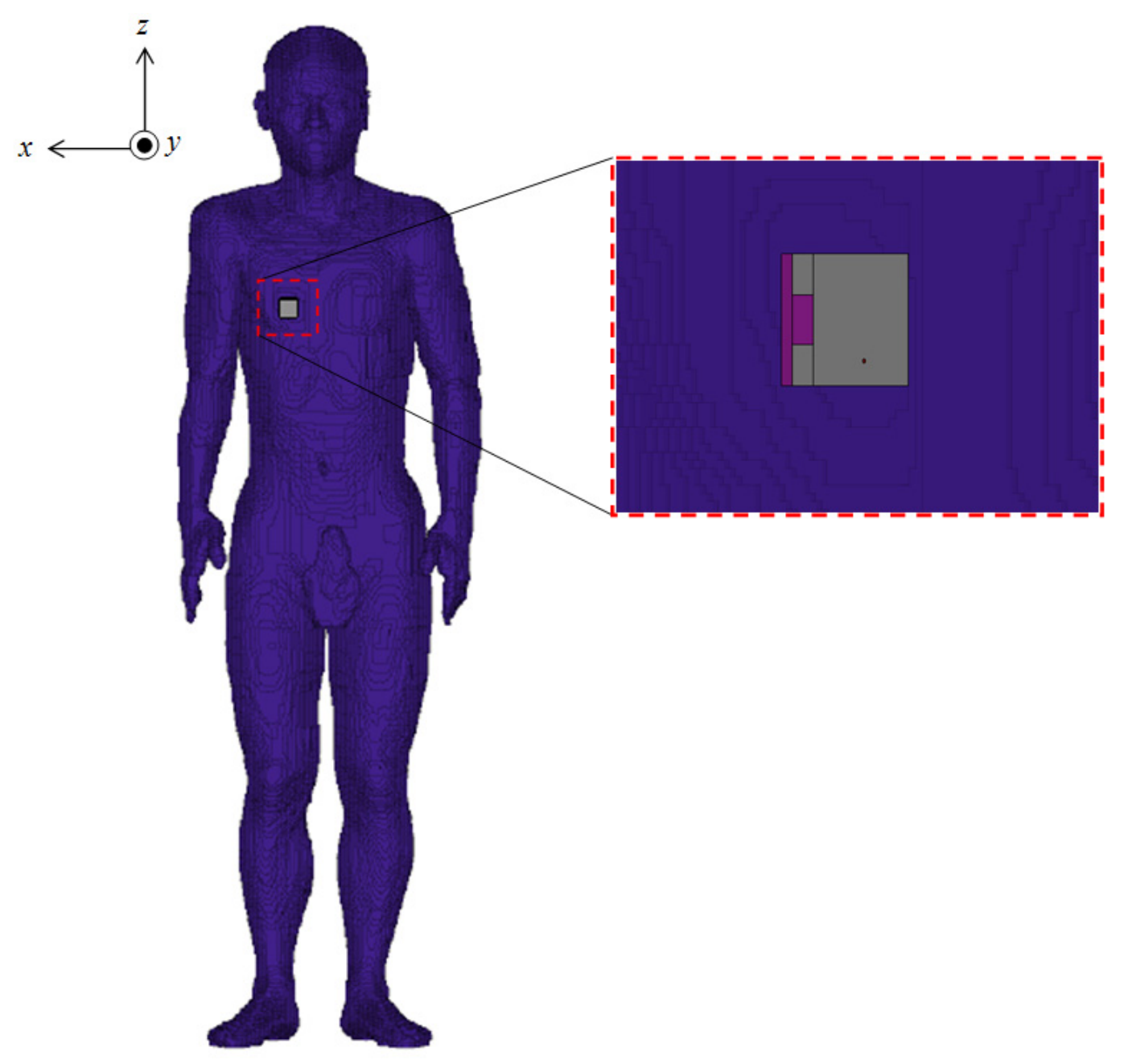

\section{Results and Discussion}

Because the proposed dual-mode antenna is designed to support on-body and off-body communications in medical applications, its characteristics in the on-body and off-body modes will be discussed in this section. In this work, we will discuss received voltage and electric field distributions for on-body communications at $10 \mathrm{MHz}$ and reflection coefficients $\left(S_{11}\right)$ and radiation patterns for off-body communications in ISM band $2.45 \mathrm{GHz}$. All the results are calculated by finite-difference time-domain (FDTD) method with a high-resolution human body and measured with a chest phantom.

\subsection{On-Body Communications}

In this section, we will evaluate the performance of the proposed dual-mode antenna for on-body communications. Figure 7 presents the simulation setup and received voltage results. The proposed antenna is installed at all the transmitters and receivers; all are attached to the chest phantom $(610 \times 370 \times 70 \mathrm{~mm})$. From the result, the received voltage between the transmitter and the receiver decreases with the increasing distance. Figure 8 illustrates the normalized electric-field distribution at $10 \mathrm{MHz}$ on the surface of the chest phantom. From the result, the intensity of the electric-field distribution decayed with the increasing distance between the transmitter and the receiver. 
Figure 7. Received voltage on the chest phantom at $10 \mathrm{MHz}$ [dB].

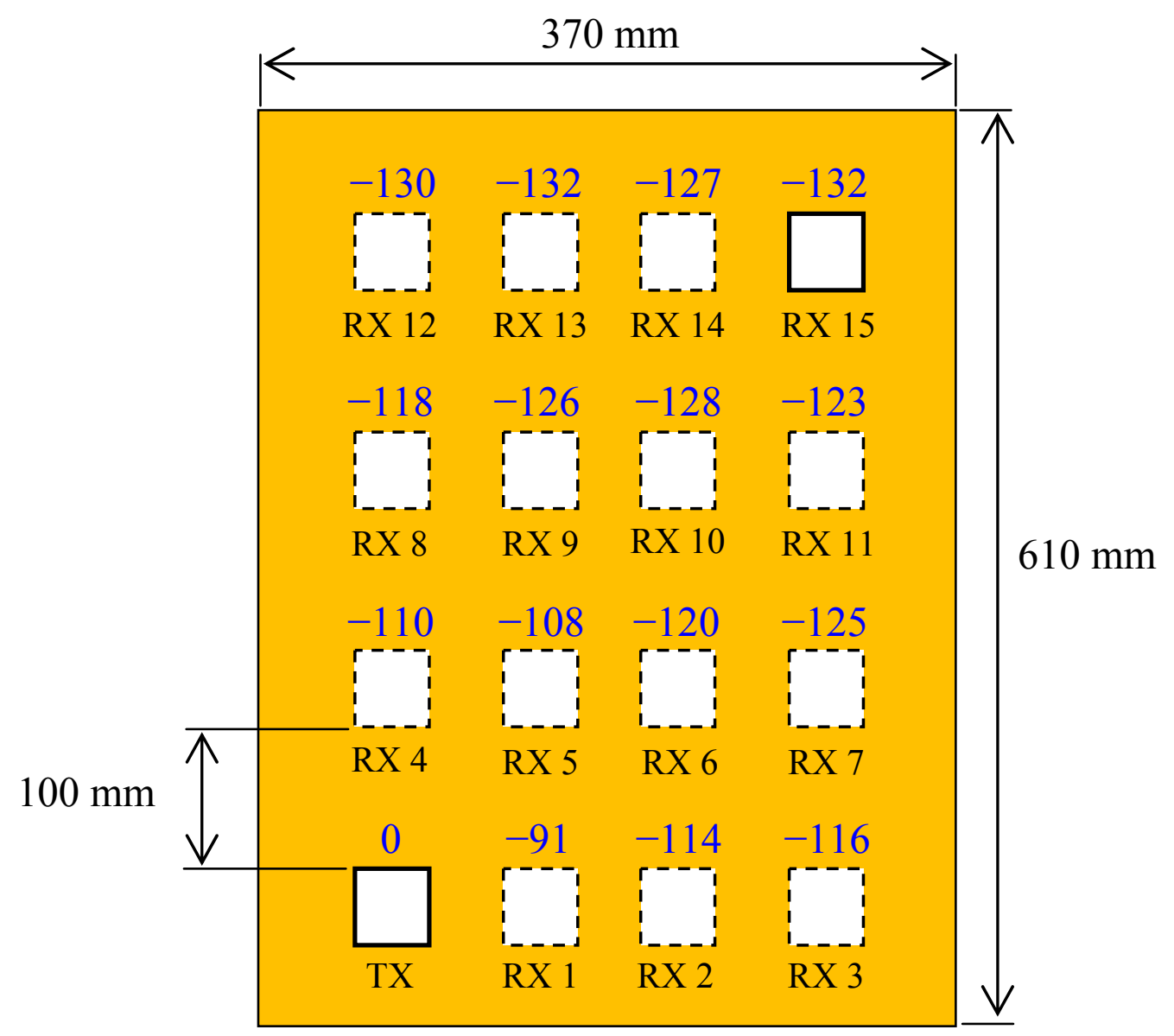

Figure 8. Normalized electric field distribution at $10 \mathrm{MHz}$.
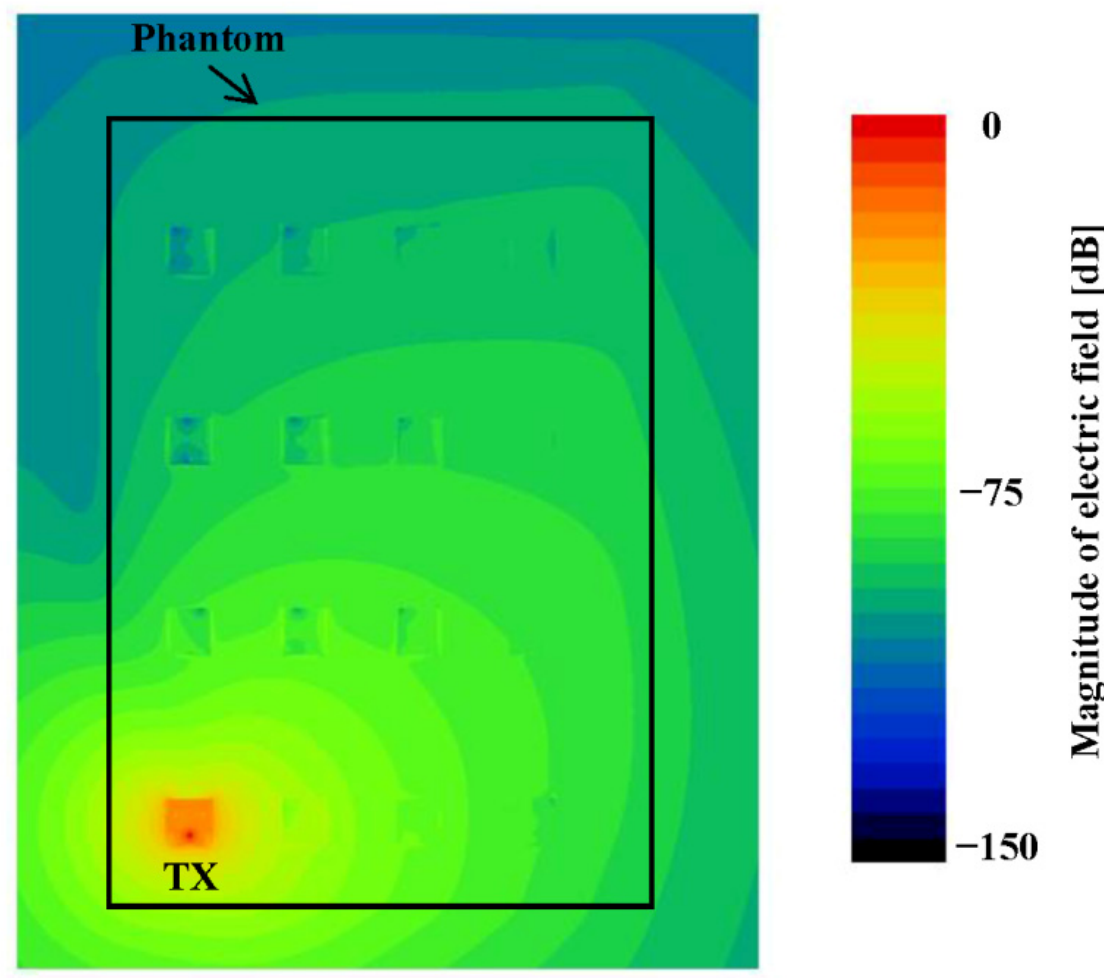
As shown in Figure 9a, one transmitter is attached to the right side of the chest while four receivers are attached on the left of the chest, right and left of the waist and stomach, respectively. Figure $9 \mathrm{~b}$ presents the variation in received voltage for the four different on-body links on the human body. From the simulated result, the received voltages are around -110 to $-160 \mathrm{~dB}$ dependence on the distance between transmitter and receiver. Figure 10 illustrates the E-field distributions inside and outside the whole human body at $10 \mathrm{MHz}$. The E-field distribution is discussed according to the received voltage that is calculated from the electric field. The observation plane includes the feeding point of the transmitter. From the results, it can be seen that the level of the electric field distribution are smooth around the human body at $10 \mathrm{MHz}$. As a result, it can be concluded that a lower frequency such as $10 \mathrm{MHz}$ is suitable for on-body communications.

Figure 9. (a) Four different on-body links and (b) variation of received voltage for four different on-body links.

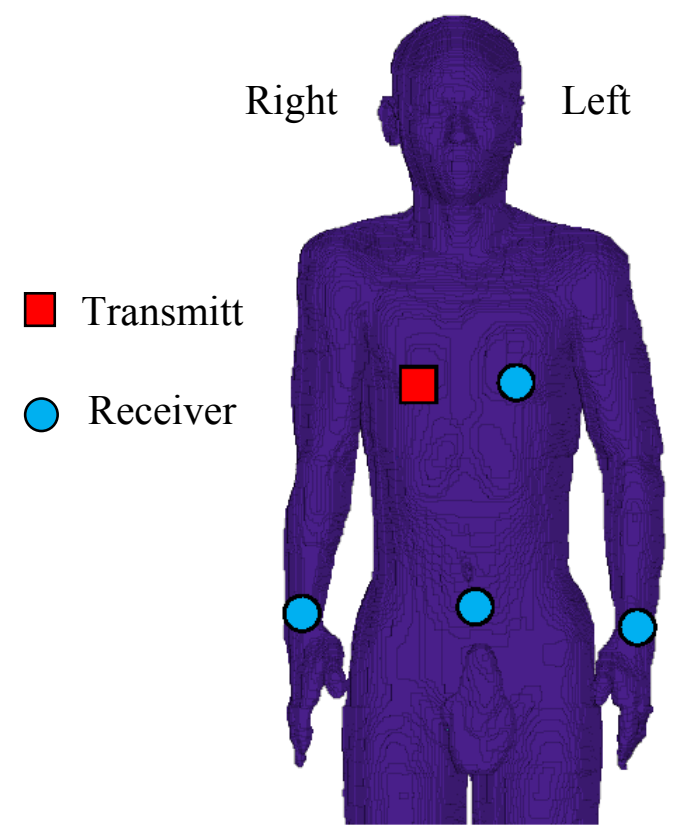

(a)

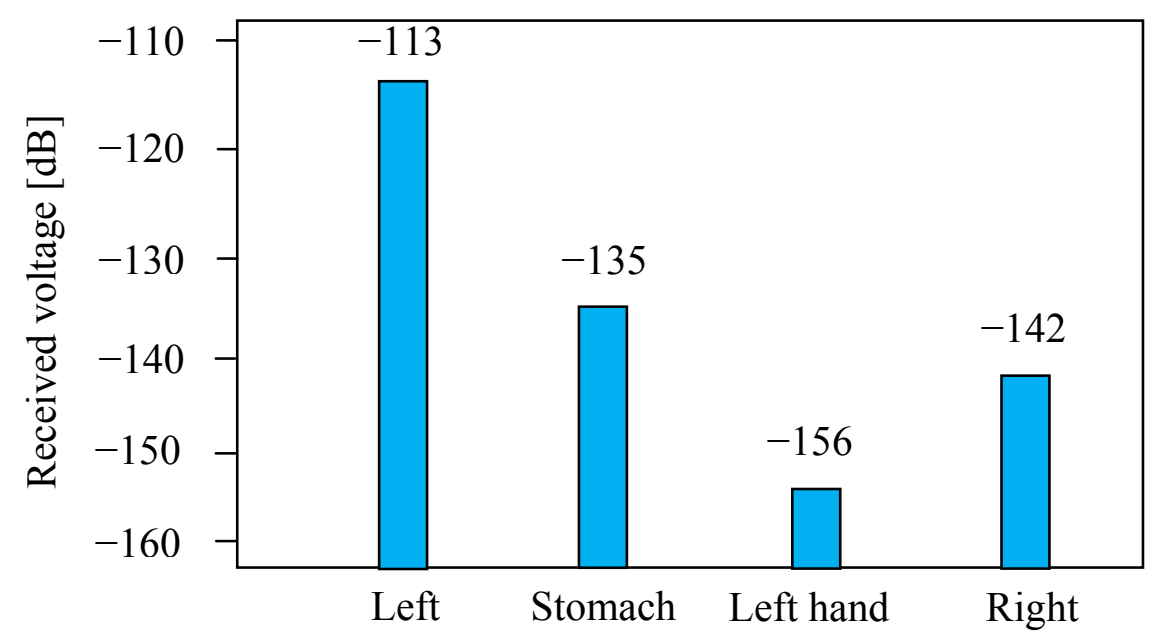

(b) 
Figure 10. Electric field distribution at $10 \mathrm{MHz}$ on a high-resolution human body.

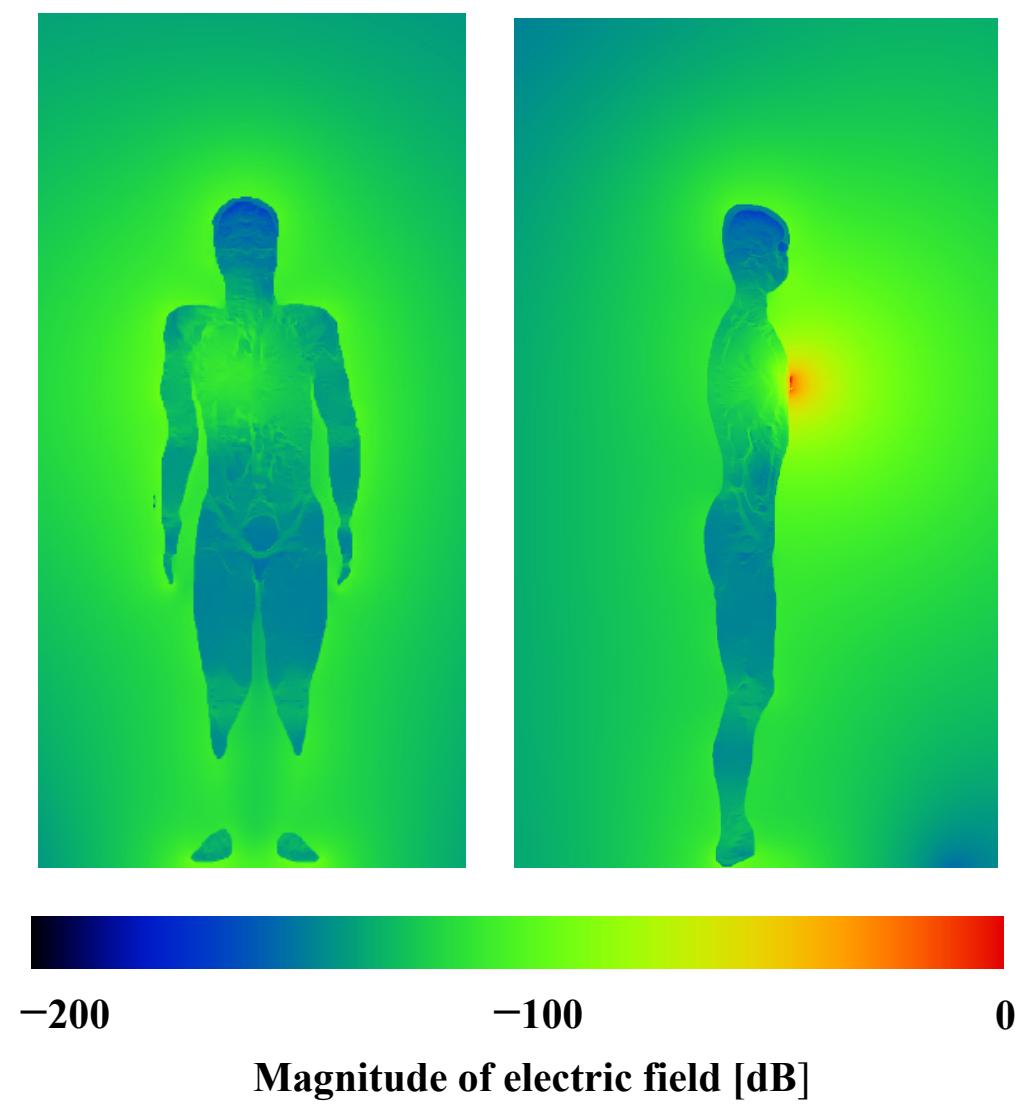

\subsection{Off-Body Communications}

We can use the off-body mode to send the received body signals (10 $\mathrm{MHz}$ on-body mode) to an external device. The performance, such as reflection coefficients and radiation patterns of the proposed antenna on a human body, is discussed here. Figure 11 presents the simulated and measured reflection coefficients when the proposed antenna is located on a part of chest phantom with dimensions of $200 \times 200 \times 70 \mathrm{~mm}^{3}$ and extended to a high-resolution human model. This antenna is found to work in ISM band $(2.45 \mathrm{GHz})$. Simulated and measured results are in good agreement. The current distribution on the proposed antenna at $2.45 \mathrm{GHz}$ is illustrated in Figure 12. The simulated radiation patterns on the chest phantom and the high-resolution human model at $2.45 \mathrm{GHz}$ in $y z$ and $x y$ planes are shown in Figure 13. From the results, the radiation patterns in both planes are relatively omni-directional with no deep nulls in the half-sphere above the human body. Therefore, the proposed antenna is a good candidate for off-body communications. In addition, the weaker radiation toward the human body is due to the absorption by human body.

Based on our experience, it is sufficient to discuss reflection coefficients $\left(S_{11}\right)$ by using a simple phantom (homogeneous); however, it may be insufficient to analyze radiation performance, such as radiation patterns. From Figure 13, the level between radiation patterns of phantom and a high-resolution human model shows a discrepancy. The main reason for this is because the high-resolution human body is inhomogeneous, causing high loss media. Therefore, the gain is weaker when the antenna is located on the whole human body. 
Figure 11. Simulated and measured reflection coefficients.

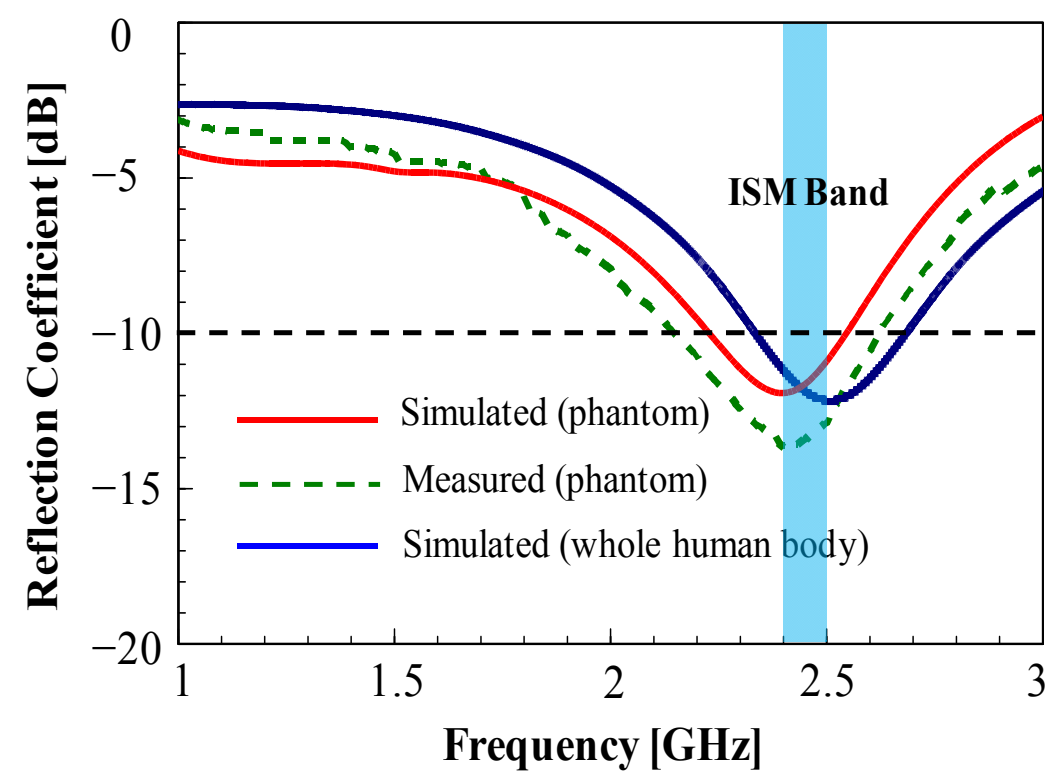

Figure 12. Simulated current distribution at $2.45 \mathrm{GHz}$.

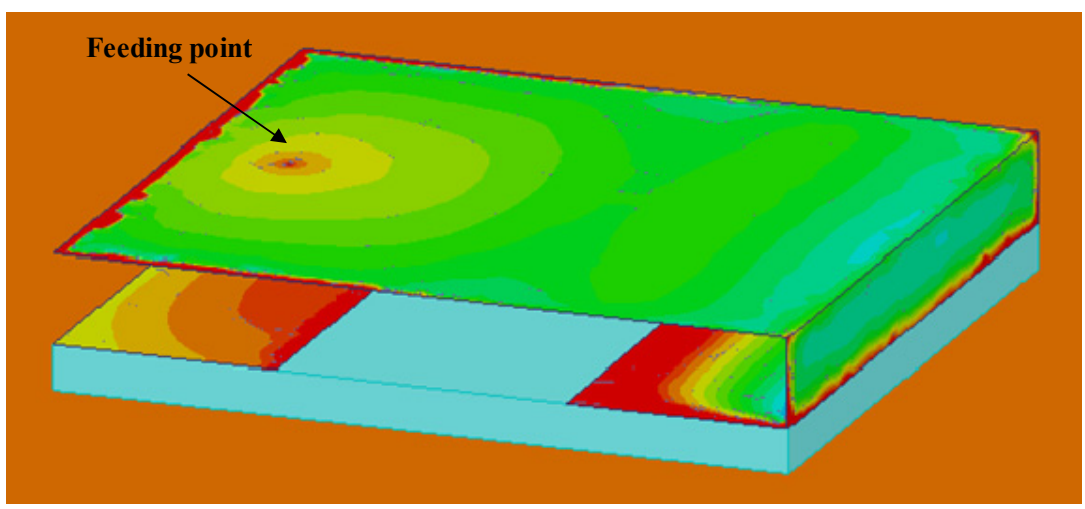

Figure 13. Simulated radiation patterns at $2.45 \mathrm{GHz}$.

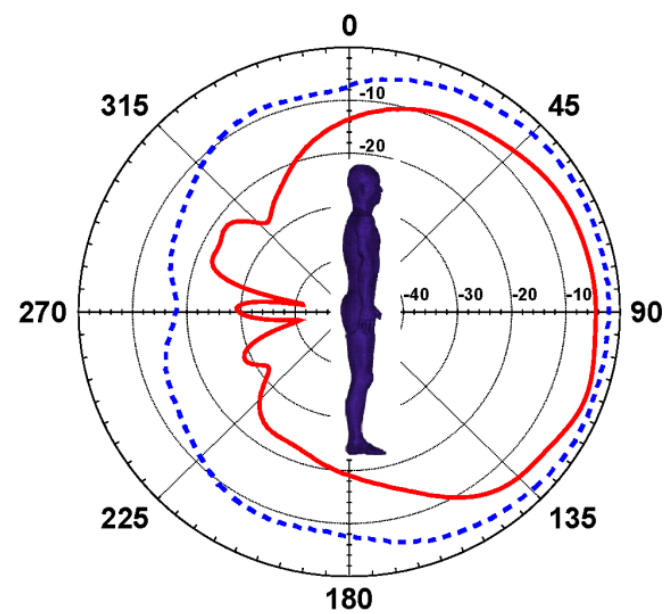

$y z$-plane

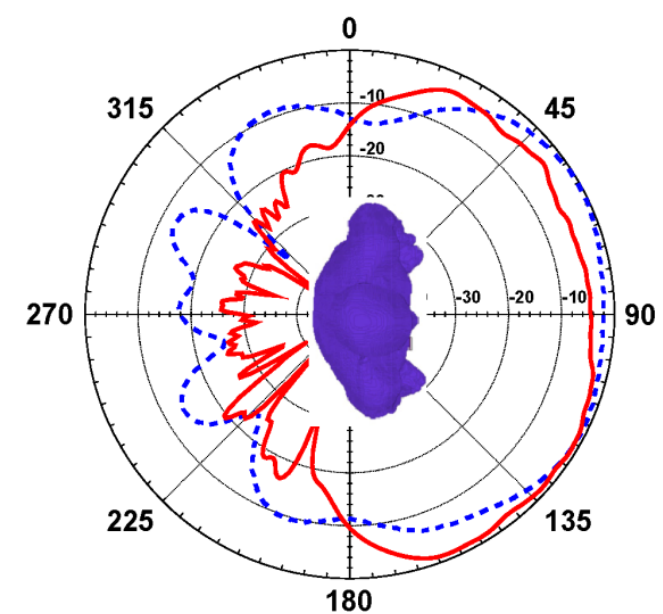

$x y$-plane

\section{High-resolution human model}




\section{Conclusions}

In this paper, we proposed a dual-mode antenna for on-body and off-body modes in medical health-care system. In on-body mode, the antenna is similar to a pair of metal electrodes operating at $10 \mathrm{MHz}$, and in off-body mode, with a folded ground structure, the proposed antenna can cover $2.45 \mathrm{GHz}$ in ISM band. To validate the antenna, received voltage and electric field distribution at $10 \mathrm{MHz}$, reflection coefficient and radiation patterns in the ISM band $2.45 \mathrm{GHz}$ are discussed on a chest phantom and a high resolution human model. The results show that the proposed dual-mode antenna can be applied in on-body and off-body communications for medical applications.

In the near future, a high-resolution whole human body model and a new standard $(21 \mathrm{MHz})$ for human body communication (HBC) announced by IEEE 802.15 .6 will be discussed in our work.

\section{Acknowledgments}

The authors would like to thank Takahashi and Saito in Chiba University and Li in Fujitsu Laboratories Ltd. for their useful comments.

\section{Conflicts of Interest}

The authors declare no conflict of interest.

\section{References}

1. Hall, P.S.; Hao, Y. Antennas and propagation for body-centric wireless communications. In Proceedings of the First European Conference on Antennas and Propagation, 2006, Artech House, Norwood, MA, USA, 6-10 November 2006.

2. Hall, P.S.; Yang, H.; Ito, K. Guest editorial for the special issue on antennas and propagation on body-centric wireless communications. IEEE Trans. Antennas Propag. 2009, 57, 834-836.

3. Haga, N.; Saito, K.; Takahashi, M.; Ito, K. Characteristics of cavity slot antenna for body-area networks. IEEE Trans. Antennas Propag. 2009, 57, 837-843.

4. Alomainy, A.; Hao, Y.; Davenport, D.M. Parametric study of wearable antennas with varying distances from the body and different on-body positions. In Proceedings of the IET Seminar on Antennas Propagation for Body-Centric Wireless Communications, London, UK, 24 April 2007; pp. 84-89.

5. Hertleer, C.; Rogier, H.; Vallozzi, L.; van Langenhove, L. A Textile Antenna for off-body communication integrated into protective clothing for firefighters. IEEE Trans. Antennas Propag. 2009, 57, 919-925.

6. Ito, K.; Haga, N. Evaluations of Body-Centric Wireless Communication Channels in a range from $3 \mathrm{MHz}$ to $3 \mathrm{GHz}$. Proc. IEEE 2012, 100, 2356-2363.

7. Lin, C.H.; Li, Z.; Ito, K.; Takahashi, M.; Saito, K. Dual-mode Antenna for on-/off-body Communications (10 MHz/2.45 GHz). Electron. Lett. 2012, 48, 1383-1385.

8. Lin, C.H.; Ito, K.; Takahashi, M.; Saito, K. Multi-functional small antennas for health monitoring systems. In Proceedings of the 2013 International Symposium on Antenna and propagation, Nanjing, China, 23-25 October 2013; pp. 569-572. 
9. Lin, C.H.; Takahashi, M.; Saito, K.; Ito, K. A compact Planar Inverted-F Antenna for $2.45 \mathrm{GHz}$ On-Body Communications. IEEE Trans. Antennas Propag. 2012, 60, 4422-4426.

(C) 2014 by the authors; licensee MDPI, Basel, Switzerland. This article is an open access article distributed under the terms and conditions of the Creative Commons Attribution license (http://creativecommons.org/licenses/by/3.0/). 